\title{
A DISCIPLINA DA EDUCAÇÃO FÍSICA ESCOLAR E SUA IMPORTÂNCIA PARA O DESENVOLVIMENTO COGNITIVO DA CRIANÇA
}

\author{
André Palma ${ }^{1}$ \\ Enrique Carlos Ferreira Silva ${ }^{2}$
}

\section{Resumo}

As aulas de Educação Física são sempre um diferencial no cotidiano de uma escola e esse destaque se torna mais evidente em escolas públicas onde na maioria das vezes existe uma carência de recursos e de atividades alternativas para os alunos. Essa disciplina promove grandes desenvolvimentos na constituição física e emocional das crianças o que faz dessa aula uma das mais significativas e esperadas pelos educandos. É nesse sentido que entendemos essa área do conhecimento ser de fundamental importância para o aprendizado do ensino básico da criança.

Palavras Chaves: Educação Física. Escola. Cognitivo. Criança

\section{INTRODUÇÃO}

Quando associamos a capacidade de uma escola desenvolver um espaço de interação social devemos pensar em sua capacidade de gerar uma boa sensação de convivência entre os alunos. Certamente que aulas realizadas de forma apenas sistemáticas não seriam capazes de criar um ambiente inovador para a sociabilidade dos alunos.

Em se tratando de aulas dinâmicas como as de Educação Física, essa característica inovadora deve ser ainda mais destacada pois aulas desta natureza já possuem em si próprias o prazer do aluno em estar participando. Os processos didáticos pedagógicos escolares, devem colaborar na formação das crianças , ajudando-as a dominar os caminhos necessários que cada vez mais as aproximem com a convivência em sociedade.

Na Lei de Diretrizes e Bases que é o Parâmetro do Ensino em nosso país, demonstra-se essa a importância que o Estado tem em garantir "padrões mínimos

\footnotetext{
1 Mestre em Ciência da Educação pela Faculdade Interamericana de Ciências Sociais - FICS; Especialista em Educação Inclusiva; Especialista em Atividade Física aplicada a Cardiologia; Licenciado em Educação Física pela UCSAL - BA; Docente em Educação Física na Prefeitura Municipal de Camaçari - BA; E-mail: andrepalma.adv@gmail.com

${ }_{2}^{2}$ Mestre em Ciência da Educação pela Faculdade Interamericana de Ciências Sociais - FICS;; Especialista em Metodologia em Educação Física e Esportes para o Ensino Básico e Superior pela UNEB; MBA em Gestão do Esporte pela UNYLEYA;MBA em Marketing Esportivo pela UNYLEYA; Graduado em Licenciatura em Educação Física pela UFBA; Docente dos Cursos de Formação Continuada de Esporte Adaptado da FBDP nas modalidades Atletismo, Natação e Voleibol Sentado; Docente no Colégio Estadual Professora Georgina Ramos da Silva - Salvador/BA; Docente na Escola Municipal Ilay Garcia Ellery - Camaçari/BA. Email - enriquefbc@hotmail.com
} 
de qualidade de ensino definido como a variedade e quantidade mínimas, por aluno, de insumos indispensáveis ao desenvolvimento do processo de ensino aprendizagem" (LDB, 1996, art. 4 , inciso IX)

A escola deve ser um local onde o ensino e da aprendizagem necessitam de uma constante superação e produção de conhecimentos para tornar o aluno capaz de pensamentos e atitudes cada vez mais elaboradas e criativas. Conceder espaços físicos adequados para as aulas de Educação Física capacita a formação do aluno fazendo com que este desenvolva diversas atividades lúdicas aprimorando sua capacidade enquanto sujeito crítico da realidade social em que se vive.

As escolas públicas em nosso país vivem uma realidade dramática que dificulta bastante a dinâmica das aulas de Educação Física e bem observada por BRACHT (2003) onde relata que, "a Educação Física se depara com o problema de suprimento de materiais para aplicabilidade das aulas, assim como a manutenção das quadras esportivas ou ainda a construção destas". E adicionado a esse problema comenta colaborando com o entendimento de que, "quanto à questão do espaço, o tratamento ao conhecimento nessa área, articulado organicamente à organização do tempo, exige que na escola se construam espaços diferenciados das outras disciplinas" (SOARES, 1992, p.38).

De forma já sedimentada na estrutura escolar, as aulas de Educação Física ganharam uma grande importância enquanto componente curricular obrigatório na educação básica, despertando um interesse por parte dos alunos em interagirem nessas aulas dentro do ambiente escolar, sendo o momento em que a criança ganha uma oportunidade de ter um aprendizado mais elaborado em atividades de jogos e de esporte .Em muitas das vezes o que mais impacta nesse desenvolvimento cognitivo do aluno é a falta espaços físicos e materiais esportivos adequados.

\section{A Didática Pedagógica das Aulas}

O objetivo do presente artigo é estudarmos as características qualitativas dos espaços, condições físicas e materiais para as aulas de Educação Física. Para entendermos melhor esse tipo de estudo podemos recorrer a um conceito em que devemos fazer uma análise sobre o ponto de vista que "a finalidade da pesquisa qualitativa é compreender como os sujeitos experimentam, percebem, criam, modificam e interpretam a realidade em que se encontram imersos" (GAYA e COLL, 
2008, p. 56).

Um fator imprescindível é compreender a importância dos espaços físicos para as aulas de Educação Física. É necessário perceber que um dos fatores essenciais para a Educação Física é promover novos caminhos e novas tendências às práticas pedagógicas, pois:

Para que este feito seja alcançado os espaços e infraestruturas escolares, devem consistir em um ambiente instigador e que os recursos didáticos pedagógicos disponíveis atendam às necessidades dos alunos (BRASIL, 1997, p.27).

É necessária uma compreensão de que o ambiente escolar precisa ser um espaço em que o aluno se aproprie da sua cultura local. E o professor deve facilitar essa apropriação dando prioridade a qualidade daquilo que é ensinado, garantindo a transmissão do conhecimento de modo adequado, uma vez que que:

\begin{abstract}
A ausência ou precariedade do espaço físico nas escolas para as aulas de Educação Física podem ser observadas sob dois aspectos: o da não valorização social desta disciplina (que acaba desvalorizando o desenvolvimento integral do educando) e o descaso das autoridades para com a educação destinada às camadas populares (DAMÁZIO E SILVA, 2008, p.189).
\end{abstract}

A construção ou mesmo a reparação de novos ambientes e espaços para a realização de aulas de Educação Física não é o suficiente para uma boa qualidade da aula. A qualidade no profissional e disponibilidade de material adequado são também fatores preponderantes que influenciam diretamente na aula. Este artigo, vem ajudar na observação de como é importante que as aulas de Educação Física tenham uma estrutura escolar adequada e eficiente para uma aula de qualidade.

\title{
A Aplicação das Aulas de Educação Física
}

Compreender como são desenvolvidas as aulas de Educação Física nas escolas públicas e sua prática pedagógica é o foco do presente artigo. Podemos observar que é justamente no ensino fundamental I que as crianças se apropriam de habilidades motoras que desenvolverão ao longo da vida. É nesse entendimento que "devemos conhecer as bases teóricas da prática, [...] não esquecendo que a teoria nasceu da prática, isto é, de múltiplas tentativas realizadas pelo ser humano em seu devir de variadas tentativas práticas" (TRIVINÕS, 2006, p.125).Nessa mesma observação pode-se afirmar que: 
A Educação Física 'amplamente' é uma prática pedagógica de atividades expressivas corporais, como jogo, esporte, lutas, dança, ginástica, etc, formas estas que representam a área de conhecimento que é chamada de cultura corporal (SOARES 1992, p. 50).

Isso porque a criança que tem a oportunidade de ter contato como o maior número de atividades físicas possíveis notadamente se desenvolverá melhor.

Faz-se necessário ter visão avançada de Educação Física escolar de qualidade e que passa necessariamente por um entendimento muito bem observado que salienta a respeito da importância da prática pedagógica na educação , sendo ela "uma prática social orientada por objetivos, finalidades e conhecimentos, e inserida no contexto da prática social. A prática pedagógica é uma dimensão da prática social"( VEIGA, 1992, p. 192) .

Analisando as aulas de Educação Física de uma forma mais profunda conseguimos estabelecer uma estreita ligação entre a as atividades práticas dos jogos e exercícios e a convivência social entre os alunos como relata, TRIVIÑOS (2006), e é o que nos ajudará a entendermos esse fenômeno educacional como parâmetro para um diálogo sobre a disciplina . O autor nos explica a importância das atividades práticas das aulas para o aprimoramento do convívio social dos alunos. Acumulando esses conhecimentos as crianças enquanto seres humanos se encontram em si mesmos e constroem sua história no processo de ensino e aprendizagem. E dessa forma, relata:

Por um lado ação, prática, e por outro lado, conceito dessa prática que se realizou no mundo dos fenômenos materiais e que foi elaborado pela consciência que tem a capacidade de refletir essa realidade material [...] refere-se sempre à totalidade do processo social de atividade material e não as atividades individuais (TRIVIÑOS, 2006 p.121).

Entendermos a prática pedagógica das aulas de Educação Física como uma oportunidade para o aluno desenvolver um adequado convívio social é muito importante. É uma construção sócia educativa visionaria que promove além de uma adequada prática pedagógica também uma inclusão social determinante na vida da criança. Esse avanço cognitivo experimentado nas aulas ganha um destaque e um importante reconhecimento dos exercícios físicos e dos jogos. Os agentes escolares são os responsáveis em facilitar a apropriação desse conhecimento pedagógico proposto pelas aulas de Educação Física onde os atores principais devem ser os 
alunos.

A vida diária nas aulas de Educação Física nas escolas e até mesmo em outras disciplinas deve ter o foco em uma convivência geral e autônoma entre os alunos. Professores e outros colaboradores devem realizar as intervenções necessárias para o convívio saudável entre as crianças.

Existem algumas práticas pedagógicas usadas por professores de Educação Física que podem nos ajudar no conhecimento didático dessa disciplina. As aulas de Educação Física têm uma peculiaridade muita grande no que tange a interação e ludicidade entre os alunos e quando o professor se torna um colaborador nesse processo se inserindo nele a aula se torna bastante agradável.

As aulas de Educação Física são as mais esperadas pelas crianças justamente por essa capacidade de juntar conhecimento pedagógico com brincadeiras e jogos. A facilitação realizada pelo professor deve ser realizada de forma incisiva e sutil para que ele participe desse processo de ensino e aprendizagem permitindo o máximo de autonomia entre os alunos.

Dificuldades estruturais das escolas e das condições das aulas tais como as carência de espaços físicos e a ausência de materiais não deve impedir uma aula produtiva. Adequar o que esteja disponível e ajustar a realidade da escola e dos alunos é uma das grandes tarefas que devem ser realizadas pelo professor de Educação Física. Vivemos a realidade de um país em que não adianta reclamar das condições das escolas públicas e nem das condições de ensino. Se o professor paralisar diante dessas dificuldades ele não conseguirá produzir um ensino de qualidade.

Quando o professor consegue entender a realidade em que está inserido e se adapta a ele a produtividade das aulas tendem a acontecer. A partir dai são desenvolvidas estratégias capazes de desenvolver nos alunos possibilidades inovadoras de aprendizado.

As aulas de Educação Física precisão ter uma característica inovadora para motivarem os alunos a participarem e se perceberem como parte do processo pedagógico. Essa dinamicidade reflete: 
A inovação educacional que se concretiza a partir das contribuições para superar os desafios presentes na escola, partindo da análise e reflexão que se faz do contexto sociocultural. Uma vez que a escola referida não dispõe de quadra esportiva ou outro espaço físico destinado para realização de atividades físicas, senão um pátio (TEIXEIRA, 2010, p.10)

Aulas dinâmicas devem proporcionar uma variedade de temas aos alunos onde despertem neles a vontade de aprender. As mais variadas formas de se apresentar essas temáticas é um constante desafio no planejamento da aula. Essas dimensões atitudinais devem traduzir o modo como se deve ser tratado as maneiras didático pedagógicos para fazer do aluno um agente da sua própria educação (ZABALLA, 1988).

Além da aula pratica de Educação Física propriamente dita é possível incrementar as atividades com um formato de oficinas. Surge então uma oportunidade para os alunos realizarem dinâmicas relacionadas, por exemplo, a nutrição e a ingestão de alimentos saudáveis. É uma estratégia para trazer nas aulas um conceito de Atividade Física e Saúde. Esse assunto pode perfeitamente ser tratado na aula de forma lúdica através de trabalhos em grupo e apresentações em seminários. Esse formato de aula é capaz de cumprir o objetivo de que as aulas de Educação Física em sala podem ter uma perspectiva agradável para a criança.

As oficinas que serão escolhidas devem seguir uma preferencia daquilo que está próximo a realidade dos alunos, pois a ideia é fazer da aula teórica uma atividade atraente e divertida. Um aluno acostumado com a dinamicidade das aulas de Educação Física em formatos de jogos e esporte só ira aceitar uma aula dentro de sala se for gratificante e desafiadora. Além dessas características as aulas dessa disciplina quando realizadas dentro de sala ou em auditório deve cumprir os objetivos didáticos pedagógicos no qual se propõe.

Um professor de Educação Física que entende o seu papel educacional e sua importância na vivencia escolar consegue desenvolver ótimos trabalhos mesmo em um cenário de escassez de espaços e matérias adequados. Mesmo diante das dificuldades o bom profissional utiliza do material humano para realizar os jogos e as brincadeiras.

A falta de condições adequadas para a promoção de aulas com qualidade deve ser encarada como um desafio para o professor. Atividades que exigem 
materiais didáticos que não estejam disponíveis podem ser substituídos por elementos pedagógicos que que produzam o mesmo efeito na absorção do conhecimento. Praticas corporais tais como o ensino da capoeira podem ser realizadas de forma muito simples até mesmo com somente os alunos batendo palmas e cantando. Esse universo de possibilidades em que as aulas de Educação Física podem ser realizadas utilizando muito pouco recurso é uma das grandes conquistas que didático pedagógico dessa disciplina escolar.

Situações dessa natureza que exigem grande criatividade por parte do professor muitas vezes o colocam em situação de destaque e de evidencia na unidade escolar. Esse fato deve ser encarado com muita naturalidade por toda a equipe docente e pelos gestores. O profissional não deve se deixar envolver emocionalmente com uma eventual situação de destaque ou mesmo de mitigação. Deve entender seu verdadeiro papel em educar na criança a cultura corporal, aceitar as dificuldades e as glorias dessa função e executá-la da melhor forma possível.

\section{Possibilidades e Alternativas de Superação}

A disciplina da Educação Física Escolar é fundamental para que as crianças em idade escolar do ensino básico desenvolvam habilidades que determinarão seu nível de conhecimento sobre o próprio corpo no decorrer de seu crescimento. É justamente nessa idade escolar que o aluno começa a ganhar confiança em si mesmo diante das diversas dificuldades encontradas durante os jogos esportivos e de ginástica. Conseguir acreditar na superação dos obstáculos impostas pela competitividade dos jogos esportivos e no domínio dos limites do corpo trará essa criança a certeza de que é possível superar as adversidades da existência humana.

O processo de ensino dos conteúdos da Educação Física, seguindo as diretrizes dos Parâmetros Curriculares Nacionais - PCN (BRASIL, 1997), nos garante uma autenticidade dos assuntos que devem ser transmitido para cada faixa etária de ensino. Essa normativa no âmbito federal serve de base para o trabalho do professor que desenvolverá atividades voltadas para os esportes, as brincadeiras, os jogos, os exercícios de ginastica, as lutas, e as atividades rítmicas e danças que trabalhadas tanto em conjunto quanto separadamente trarão uma característica singular para as aulas de Educação Física.

Ao professor caberá passar esse conteúdo da forma mais lúdica possível 
sendo essa uma das grandes atribuições tanto da aula quando do profissional de ensino. Entendemos inclusive que esse diferencial relacionado a ludicidade das aulas de Educação Física é o motivo determinante que causa grande motivação nas crianças em realizar as atividades.

O amor a profissão e quando o professor consegue ver que o aluno aprendeu ou mesmo que se divertiu na aula é uma das maiores gratificações que o profissional pode vivenciar. A disciplina da Educação Física traz em seu processo de ensino e aprendizagem uma interação entre aluno e professor que somente se pode experimentar nessa área do conhecimento. É por esse motivo que não poucas vezes ouvimos adultos relatarem que é a aula que mais gostavam durante o ensino básico.

Outra importante observação é aquela que diz respeito ao ambiente escolar de ensino fundamental I que tem o privilégio de haver em seu currículo escolar aulas de Educação Física ministrada por professores especialistas. Quando isso acontece a escola passa se torna um ligar mais agradável, descontraído e os alunos aprendem melhor as outras disciplinas. Evidente que não basta a disciplina estar incluída no contexto escolar e ter professor para ensinar.

Os esportes realizados devem estar diretamente relacionados com a realidade social do local onde ela está inserida. Esse requisito é bem observado quando esclarece que "o esporte precisa ser questionado em suas normas, suas condições de adaptação à realidade social e cultural que o pratica, cria e recria" (SOARES, 1992, p.71).

O presente artigo busca demonstrar, além de outros conceitos, que é possível realizar uma excelente aula de Educação Física mesmo em escolas que carecem de toda disponibilidade de materiais, espaços ou mesmo material humano. A transmissão do conhecimento e a apropriação pelo aluno pode ser realizada através de uma interação entre os agentes participantes desse processo.

O professor não deve deixar que o ensino e a aprendizagem se limitem ao material didático ou espaço físicos disponíveis. Essa dificuldade é muito bem ressaltada por BRACHT (1999, p. 39) onde afirma que: "a existência de materiais e espaços físicos específicos para a Educação Física é importante e necessária, sua ausência ou insuficiência podem comprometer o trabalho do professor", pode muito 
bem ser superada com um eficiente planejamento e trabalho pedagógico inovador.

Não há dúvida que o ideal para que uma aula de Educação Física seja realizada com qualidade é importante a disponibilidade de materiais esportivos adequados e espaços físicos suficientes. Buscar a melhor forma de obter essas condições ideais deve ser uma constante tarefa do professor, pois:

\footnotetext{
Uma infraestrutura ideal possibilita vivências corporais consoantes com as danças, as ginásticas, as lutas, os jogos, entre outras possibilidades, favorecendo ao aluno, parte principal desse processo de desenvolvimento (CARVALHO e BAHIA, 2011, [s.p.])
}

A superação é a base do ensino público em nosso país. Não seria diferente pensar nas aulas de Educação Física sem visualizar essa superação. Conseguiremos avançar para uma boa qualidade de ensino sempre que pensarmos nas aulas como um momento singular para crescermos como seres humanos.

\section{Uma Visão Especial Para a Educação Física}

É possível percebermos que nos tempos atuais a utilização de metodologias diversificadas junto as inovações tecnológicas têm trazido significativas mudanças para as aulas de Educação Física. Essas transformações têm servido para tirar o estigma de que as aulas dessa disciplina têm servido apenas para perpetuar velhos conceitos políticos sociais. Vale destacar que:

A Educação Física, muitas vezes, tem servido de poderoso instrumento ideológico e de manipulação para que as pessoas continuem alienadas e impotentes diante da necessidade de verdadeiras transformações no seio da sociedade (CASTELLANI, 1988, p.11).

Atualmente as aulas de Educação Física como disciplina obrigatória no ensino básico tem tentado a superação do conceito trazido no paragrafo anterior pelo autor. $\mathrm{O}$ foco tem sido agregar à matéria um contexto emancipador para o aluno. Cada vez mais o conteúdo didático pedagógico da disciplina tem sido no sentido de democratizar os conceitos de jogos e brincadeiras criando na criança um entendimento de que ela é capaz de mudar a realidade ao seu redor.

Quando é demonstrada para o aluno dentro das aulas de jogos e esportes que ela é além de educanda uma pessoa autônoma em sua forma de pensar a criança como a sentir confiança em si mesma. Essa mudança interna na forma de 
pensar traz inúmeros benefícios quando são repetidos diversas vezes durante o ano letivo.

Esse processo de crescimento cognitivo do aluno é percebido a medida que aumenta a intensidade de sua participação nas aulas. O aluno começa a se perceber incluído em um contexto social fazendo parte dele , assim como "a escola é uma instituição social, e como tal, se encontra numa relação dialética com a sociedade em que se insere" (GONÇALVES,1994 p. 32)

Quando a criança pula, salta, alonga ou mesmo realiza uma corrida ela sente um prazer muito grande principalmente quando essa atividade é realizada no contexto escolar. Mas é mais precisamente nos jogos esportivos que os alunos desenvolvem uma das suas maiores habilidades no quesito corporal e na interação uns com os outros.

As aulas de Educação Física realizada na escola tem essa incrível capacidade de trazer uma imensa satisfação ao aluno durante o dia em que ocorre essa disciplina. $O$ dia do professor de Educação Física é um dos mais esperados pelas crianças durante a semana. Fazer a criança correr, se exercitar e jogar com seus colegas faz com que diversas funções motoras e cognitivas sejam desenvolvidas pelo aluno. Jogos de futebol, handebol, basquete e vôlei encontram uma adesão quase que por todos os alunos presentes na escola. Até mesmo as crianças com necessidades especiais de diversas naturezas encontram nessas aulas uma forma de se incluírem no contexto escolar de ensino regular.

Sendo o dia dessa disciplina a mais esperada pelos alunos do mesmo trás uma importante responsabilidade para o professor. O especialista nessa área do ensino deve ter todo um olhar diferenciado para fazer com que as aulas atinjam a expectativa do aluno. A aula de Educação Física é uma disciplina muito importante para o desenvolvimento cognitivo e social do aluno no ensino básico. Os estímulos corporais desenvolvidos durante a execução das atividades é um acontecimento continuo e fundamental na fase infantil da criança (GONÇALVES, 1994).

Se a aula de Educação Física coincide, por exemplo, com um dia chuvoso e na escola não tem uma quadra ou espaço coberto para fazer a atividade física os alunos ficam tristes. Nesse momento o professor pode aproveitar para trabalhar em sala com os alunos sobre as regras dos esportes e a convivência social. E ainda 
pode aproveitar para realizar conversas sobre os sentimentos dos alunos diante de certas frustrações que podem ocorrer durante os jogos esportivos como por exemplo aceitar perder em um jogo ou brincadeira.

Transformar os alunos em bons jogadores não é o intuito das aulas, mas sim trazer para o aluno o prazer de jogar e treinar esse conceito está inserido na existência de uma mecânica corporal da criança que a transforma em uma perfeita máquina humana e onde o seu corpo se torna apto ao aprendizado tanto para uma série de movimentos como estabelece de forma progressiva normas sociais para realização desses movimentos (DAOLIO,1995).

Os conteúdos pedagógicos das aulas de Educação Física vão além das atividades esportivas propriamente ditas. Aulas contendo o ensino de ritmos e danças e ritmos são realizadas para incrementar o conhecimento da corporeidade dos alunos. As diversas danças que compõe nossa cultura regional permitem que toda essa cultura local seja trabalhada em forma de aulas praticas e dinâmicas. A contribuição da disciplina de Educação Física na cultura folclórica em nossa região é bastante significativa visto que durante as aulas podemos realizar diversas dessas manifestações como é o caso das aulas de capoeira.

Nos tempos atuais se formos analisar os aspectos da realidade na Educação Física escolar veremos que foi deixado um pouco de lado as tendências preconceituosas que ocorriam durante as aulas. Evidente que alguns estigmas relacionados a composição corporal e habilidades físicas ainda persistem no entanto em um menor grau. Muito dessa evolução se deve justamente as legislações e informações sobre o conceito de inclusão dentro das escolas. Esse conceito de escola inclusiva tem tomado as aulas de Educação Física e tem podido trazer uma nova realidade para essa disciplina. As crianças são instruídas a viver com o diferente e aceitar as limitações de seus colegas.

Durante as praticas diárias das aulas de Educação Física nas escolas nem todas as crianças desenvolvem na mesma velocidade as habilidades necessárias para prática esportiva. Em se tratando do ensino fundamental I essa observação é ainda mais destacada por se tratar de alunos no inicio dos seus ciclos de aprendizagem mais aprimorada. As crianças brincando e jogando em seus 
momentos de maior descontração na escola é uma grande experiência (PICCOLO,1993).

Vale salientar que ao vermos de forma natural os movimentos das crianças ao realizarem as aulas de Educação Física quando elas correm, andam, saltam, giram, arremessam apresentando dessa forma significativas atitudes corporais que demonstram uma cultura corporal manifestada claramente com características do local onde vivem, sendo assim:

\footnotetext{
[...] a criança-corpo que brinca, pula, corre, chora ou emburra muitas vezes visualiza seus movimentos sob a perspectiva da execução, e assim deixo de perceber o corpo-sujeito que comunica com o ambiente através de sua intencionalidade e ação[...]"(PICCOLO, 1993, p.136).
}

Esses momentos para as crianças é um dos mais esperados durante as suas atividades escolares. As aulas de educação Física trazem a capacidade da criança vivenciar na escola momentos de intensa aprendizagem afetiva e emocional potencializado através de um convívio social saudável entre seus colegas de escola. Mesmo com todas as dificuldades que permeiam o ensino público em nosso país a disciplina da Educação Física ainda é um diferencial no cotidiano escolar desses alunos. Os momentos dos esportes, jogos e brincadeiras realizados nessa disciplina ao longo da vida escolar básica garantem lembranças nesses alunos que iram os acompanhar pelo resto da vida.

\section{Considerações Finais}

Devemos observar as aulas de Educação Física como de fundamental importância para o desenvolvimento cognitivo e social da criança. Esse conceito já é largamente aplicado em diversos países em que o ensino da motricidade humana é de importância fundamental. Considerar o ensino da cultura corpórea tão importante como o ensino de outras disciplinas pode evidenciar o nível de desenvolvimento de uma nação.

O processo de desenvolvimento e amadurecimento do ensino e aprendizagem das Aulas de Educação no ensino público passa pela conscientização da importância dessa disciplina pela população e pelas políticas públicas. É necessária que se torne obrigatório o ensino da Educação Física por profissionais 
especialistas em todas as etapas do ensino básico e principalmente nos anos iniciais.

Faz-se necessário dar a essa área do conhecimento a verdadeira importância que a matéria tem na vida das crianças. Vivenciar desde pequenas idades atividades como jogar, brincar, praticar esportes e conviver com outros colegas durante essas atividades é fundamental para o desenvolvimento cognitivo do aluno.

Essa visão contemporânea permite que crianças tenham desde cedo a oportunidade de saber lidar com os desafios da sua condição corporal e junto a isso possam entender e participar do convívio social necessário para a realização dessas atividades. Não temos a menor dúvida de que ao permitir uma Educação Física de qualidade durante a vida escolar do aluno o coloca em uma situação de um importante desenvolvimento cognitivo e social.

\section{Referências:}

BRACHT, V. A constituição das teorias pedagógicas da educação física. Cadernos Cedes, ano XIX, n 48, Agosto, 1999.

\section{CARVALHO; BAHIA. I Congresso de Educação Física do Sul da Bahia}

CASTELLANI FILHO, Lino. Política educacional e educação física. Campinas. Autores Associados, 1998.

DAMAZIO, M. S.; SILVA, M. F. P. O ensino da educação física e o espaço físico em questão. Pensar a Prática, v.11, n. 2, p. 197-207, mai./ago. 2008.

DAOLIO, J. Educação Física e o conceito de cultura. Campinas, SP: Autores Associados, 2004.

GAYA, ADROALDO e Coll. Introdução a Metodologia da Pesquisa. Porto Alegre: Ed. Artmed, 2008.

GONÇALVES, M. A. S. Sentir, pensar e agir: corporeidade e educação. Campinas, SP: Papirus, 1994.

PICCOLO, V. L. N. Educação Física Escolar: ser__ ou não ter?. Campinas: Ed. da UNICAMP, 1993. .

SOARES, C. L. et al. Metodologia do Ensino de Educação Física. São Paulo: Cortez, 1992.

TRIVIÑOS, A. N. S. Introdução à Pesquisa em Ciências Sociais: a pesquisa qualitativa em educação / Augusto Nibaldo Silva Triviños. -São Paulo: Atlas, 2006. 
TEIXEIRA, E. As três Metodologias: acadêmica, da ciência e da pesquisa. 7. ed. Petrópolis, RJ: Vozes, 2010.

VEIGA, I. P. A. A Prática Pedagógica do Professor de Didática. 2. ed. Campinas Papirus, 1992

ZABALA, A. A Prática Educativa: como ensinar. trad. Ernani F. da F. Rosa. Porto Alegre: ArtMed, 1998. 